\title{
Low level of stroke care awareness among stroke patients' caregivers: an important but neglected area of stroke care
}

\section{N. Sharma, ${ }^{1}$ M. Sharma, ${ }^{2}$ M. Lopchan, ${ }^{3}$ L. Thapa, ${ }^{4}$ PVS Rana ${ }^{5}$}

${ }^{1}$ Assistant Lecturer, Narayani Samudaik Hospital Chitwan, ${ }^{2}$ Associate Professor, ${ }^{3}$ Professor, Chitwan school of Medical Sciences, Chitwan, Nepal, ${ }^{4}$ Assistant Professor, ${ }^{5}$ Professor, College of Medical SciencesTeaching Hospital, Chitwan, Nepal

\section{ABSTRACT}

\section{Objective}

Stroke is one of the leading causes of mortality and morbidity worldwide. Stroke patients require longterm care for better outcome. Most often family members are the back bone of the service provided to people affected by stroke. Stroke patients and their caregivers are known to have large gaps in stroke knowledge and have suboptimal personal health behaviors, thereby putting the patient at high risk for complications. Our study was designed to explore the stroke care awareness among stroke patients' caregivers.

\section{Methods}

50 stroke caregivers aged $>18$ years from neurology ward of College of Medical Sciences-Teaching Hospital were selected by non-probability purposive sampling from June 2012 to July 2012. Questionnaire focusing basic stroke care was prepared by researchers with the help of literature and a neurophysician. Validity and reliability of the tools were tested and data collected. Analysis of collected data was done using SPSS 16.0.

\section{Results}

The mean age of the respondents was 40 years (range: $20-80$ years). Thirty-nine (78\%) were either spouse or children. Thirty-eight (76\%) caregivers were literate. Overall, 27 (54\%) caregivers had low level of awareness regarding stroke care and mean knowledge score was 23.7.

\section{Conclusion}

This study has revealed the existence of low level of stroke care awareness amongst stroke caregivers. Interventional education program oriented to address this important yet neglected area can improve the stroke care in countries like Nepal where recent advancement for stroke management is lacking.

\section{Key Words: Stroke; stroke care givers; stroke care awareness.}


Journal of College of Medical Sciences-Nepal, 2013, Vol-9, No-3,

\section{INTRODUCTION}

Stroke is one of the major causes of disability and death worldwide. Almost half of the patients suffering from stroke are dead by one year. ${ }^{1}$ The initial couple of month is crucial period for stroke survivors to improve their health. However, because of the lack adequate knowledge, the caregivers are unable to manage the complexity of the care needed during this period. Novice caregivers are usually inadequately prepared for their caregiving role, and hence lack the information and skills to provide appropriate care. ${ }^{2}$

Stroke patients require long-term care for better outcome. Most often family members provide assistance to community-living stroke patients. These caregivers play very important role amongst the service providers to people with stroke. Stroke patients and their caregivers have inadequate stroke knowledge and poor personal health behaviors. This large gap in stroke knowledge makes patients vulnerable for stroke related complications. ${ }^{3}$ This study was conducted to understand the existing knowledge regarding basic stroke care amongst stroke patients' caregivers, which can help design appropriate intervention programs and may enhance stroke care and outcome.

\section{METHODS}

This is a descriptive study in which conceptual framework was designed initially. The important factors presumed to help develop health promotive behaviour in caregivers which prevent secondary stroke and related complications and promote quality care were identified. Then questions focusing basic stroke care were prepared by researchers with the help of literature and a neurophysician. Questionnaire (Table 1) was divided into 2 parts; Part I: Socio-demographic data (8 questions) and Part II: Physical care (19 questions), psychological care (4 questions) and prevention from complications (12 questions).

After this, operational definitions were used which included: Caregivers were referred as family member providing assistance to stroke patients. Patient was referred as the person who was newly diagnosed or recovering from ischemic or hemorrhagic stroke as diagnosed by neurologist. Awareness regarding care of stroke patient referred to awareness about proper positioning, mobilization, enhancing self care activities, feeding, communication, emotional care and prevention from complications.

After this, validity was established and reliability of the tool maintained through pretesting. Institutional ethical clearance and written informed consent from respondents were obtained.

Then, 50 stroke caregivers aged $>18$ years from neurology ward of College of Medical SciencesTeaching Hospital were selected by non-probability purposive sampling from June 2012 to July 2012. The questionnaires were completed in a face to face survey which ensured a high response rate. This also allowed clarification of questions by the respondents and responses by the researcher. Each correct response was given " 1 " score and wrong answer " 0 " score. Then the mean knowledge score of the group was calculated and compared with knowledge score of each respondent. The level of awareness was then classified into 3 categories; high level (more than 75\%), average level (50-75\%) and low level $(<50 \%)$. All the collected data were analyzed using SPSS 16.0. 
$N$. Sharma et al. low level of stroke care.

Table 1: Categories of questions in the questionnaire

Characteristics

PART: I (Socio-

demographic

characteristics)
1. What is your age? What is your sex?

2. What is your religion?

- Hinduism, Buddhism, Christian, Islam

3. What is your educational status?

- Literate/Illiterate

- If literate, what is your level of education?

- Informal education, Primary level, Secondary level, Higher secondary level $\&$ above

4. What is your occupation?

- Farmer, Housewife, Labour, Service, Business, Others(please specify)

5. What is your average monthly income of the family?

6. What is your relation with care recipient?

- Spouse/Offspring/Relatives/Others (please specify)

7. What is your time duration of providing care to care recipient?

\section{PART II: Physical} care
8. What is the appropriate position of patient?

- Lying on affected side/Upright sitting position/Lying on unaffected side/ Supine position

9. What is the required frequency to change the position of patient?

- 1 hourly/2 hourly/3 hourly/4 hourly

10. When should the patient be mobilised at first?

- Mobilize after the condition improve/Must be in complete bed rest/ Mobilised as early as possible/Mobilised after a week of stroke

11. Is it necessary to assess the balance of patient before ambulating out of bed?

- Yes/No (If yes, what should be assessed first?)

- Balance while sitting/Balance while standing

- Do you need to use any devices for ambulation?

- Yes/No (If yes, what is the device that the patient can use at initial stage?

- Crutches/Stick/Walker/Canes

12. How often should you provide bath to patient?

- Once a week/Twice a week/Once in two week/Once a month 
Journal of College of Medical Sciences-Nepal, 2013, Vol-9, No-3,

13. What type of towel is easier to control for patient while drying after bath?

Small towel/Medium sized towel/Large sized towel/Extra large sized towel

14. What type of cloth is preferable for patient to wear?

- Loose fitting size/Normal size/Small size/Extra large size

15. What should be done if the patient has urine incontinence?

- Keep catheter/Frequently provide bed pan/Use diaper/Let him pass urine on bed

16. If the catheter is placed, how often should the catheter care be done?

- Daily/Once a week/Twice a week/Thrice a week

17. What is the proper time to change the catheter?

- At 1 week/At 2 weeks/At 3 weeks/At 4 weeks

18. What is appropriate when the patient has stool incontinence?

- Use steel bedpan/Use plastic bedpan/Put on diaper to patient/Take the patient to toilet

19. Does the stroke result in swallowing problems?

- Yes/No

20. What route is preferred if the patient has swallowing difficulties?

- Per orally/Nasogastric feeding/Parental feeding/Nil per orally

21. Is it necessary to check the tube before feeding?

- Yes/No

22. How often should you change the tube?

- $\quad$ Every week/Every 2 week/Every 3 week/Every 4 week

23. What type of food is mostly preferred?

- Highly nutritious diet/Food rich in protein/Food rich in carbohydrate/ Highly fiber diet

24. What type of food should be avoided?

- Thick liquid/Chewy or hard/Soft/Thin liquid

25. What should be assessed to monitor nutritional status of patient?

25.1 Weight of patient/Route of feeding/Appetite of patient/Diet assessment

Part II: Psychological26. Does the stroke impair patient's communication?

care

- Yes/No

27. What should be done to encourage the patient to communicate effectively?

- Talk as usual/Ignore the patient/Use gestures, pictures and objects/

Provide psychological support

28. Does the depression occur in patient?

- Yes/No 
29. What should be done to prevent depression?

- Provide educational programme/Isolate from others/Talk with patient/ Provide anti depressants drugs

PART II: Prevention 30. Does the pneumonia develop in stroke patient?

$\rightarrow \quad$ Yes/No

31. Does the deep breathing and coughing exercise should be done to prevent chestinfection?

- Yes/No

32. Does the improper position result joint deformities?

- Yes/No

33. What should be done to prevent joint deformities?

- Position change and exercise/Ambulation/Use of compressive stocking/Proper diet

34. How many times a day the affected extremities should be exercised passively?

- $1-2 / 2-3 / 3-4 / 4-5$

35. Does the pressure sore develop in stroke patients?

$\rightarrow \quad$ Yes/No

36. What should be done to prevent pressure sore?

- Position change/Put on comfortable cloth/Ambulation/Use of stocking

37. Does the elastic stocking should be used for prevention of deep vein thrombosis?

- Yes/No

38. What should be done to prevent the patient from falling while walking?

- Restrict to walk/Hazard assessment in home/Use comfortable shoe/ Advice to walk alone slowly

39. Does the chocking occur if you do not feed the patient properly?

- $\quad$ Yes/No

40. Which of the following should be prioritized while feeding per orally?

- Give thin liquids/Give smaller bolous of easily swallowing food/Give solid foods/Give chewable foods

41. Which of the following position should be prioritized while feeding through nasogastric tube?

- Keep patient on supine position/Elevate the head of bed at least 30 degree/Keep patient on side lying position/Position does not matter 
Journal of College of Medical Sciences-Nepal, 2013, Vol-9, No-3,

\section{RESULTS}

Most of the caregivers were 21-30 years of age (mean age 40 years). There were $50 \%$ male and $50 \%$ female respondents. Thirty-eight (76\%) respondents were literate with most achieving above primary level of education. (Table 2) Children and spouse of the stroke patient were found to provide care in most of the cases $(n=39 ; 78 \%)$.

Table 2: Demographic profile of the Respondents: Age, Sex and Religion

$\mathbf{n}=\mathbf{5 0}$

\begin{tabular}{|c|c|c|}
\hline $\begin{array}{l}\text { Variables } \\
\text { Age group }\end{array}$ & Frequency & Percentage \\
\hline \multicolumn{3}{|l|}{ (in years) } \\
\hline Below 20 years & 6 & 12 \\
\hline $21-30$ years & 15 & 30 \\
\hline $31-40$ years & 6 & 12 \\
\hline $41-50$ years & 7 & 14 \\
\hline 51-60 years & 9 & 18 \\
\hline $61-70$ years & 6 & 12 \\
\hline Above 80 years & 1 & 2 \\
\hline \multicolumn{3}{|l|}{ Sex } \\
\hline Male & 25 & 50 \\
\hline Female & 25 & 50 \\
\hline \multicolumn{3}{|l|}{ Religion } \\
\hline Hinduism & 43 & 86 \\
\hline Buddhism & 8 & \\
\hline Christian & 3 & 6 \\
\hline
\end{tabular}

Eleven caregivers (22\%) had awareness regarding positioning and 22 (44\%) had awareness regarding mobilization. Twenty-three (46\%) knew about the need to use devices for ambulation. Surprisingly, out of them only four (17.39\%) knew to use walker to aid walking and prevent fall at initial stages.

Thirty-one (62\%) were aware of daily catheter care and only two (4\%) caregivers knew proper time to change indwelling catheter used for urinary incontinence.

Thirty-seven (74\%) were aware of existence of swallowing problems in stroke, however $22(44 \%)$ still believed that oral feeding is acceptable mode of feeding in such situation.

Presence of communication impairment and depression were appreciated by majority of respondents $(82 \%$ and $76 \%$ respectively). Nineteen (38\%) respondents knew appropriate method to encourage communication and $29(58 \%)$ respondents were found to have awareness about management of depression appropriately by counseling with health personnel.

Thirty-one (62\%) caregivers were aware that stroke can be a risk factor for pneumonia. Only 22 (44\%) were aware of use of elastic stocking for prevention of deep vein thrombosis.

Overall $26(52 \%)$ caregivers had low level of awareness regarding stroke care. Mean knowledge score was 23.7.

\section{DISCUSSION}

This is the first study from Nepal, focusing stroke caregivers revealing the existing awareness regarding stroke care, which would help us to formulate intervention plans for better stroke outcome. 
N. Sharma et al. low level of stroke care.

This study targeted to assess the major area of stroke care known to influence the outcome in stroke patients. In our study having equal number of male and female respondents, most caregivers $(73.68 \%)$ had studied above primary level of education. This level of education is accepted by experts (Neurologists) to be adequate to learn about basic stroke care. However, most of our respondents were found to be unaware of basic stroke care. We had interviewed caregivers after seven days of hospital stay and it is evident that they have to be properly guided with structured program which is, at present, lacking in our country.

It is usual for either spouse or children to be involved in stroke care for the stroke survivors as revealed in our study. Similar was the observation by Nayeri et al where $61.5 \%$ caregivers were offspring and $38.5 \%$ were spouse. ${ }^{4}$ This group hence form a major target for intervention to bring about changes in better stroke care. However, as health services for specialty care are rapidly developing in our country, nursing home care may also be an option in future where trained personnel would provide stroke care.

Driscoll et al found that $77.5 \%$ caregivers were not given information about the usual activities that a stroke patient can do. ${ }^{5}$ In our study $78 \%$ respondents were unaware that stroke patients can perform self-care activities. This knowledge gap can have both good and worst consequences. This unawareness may make some caregivers more attentive to stroke patients and other caregivers may be frustrated and can neglect patients' care. It is not unusual for us to come across disabled stroke patients in hospital and communities and people believing that stroke is a permanently disabling disease. Inadequate knowledge, the rumors about stroke as a permanently disabling disease and caregiver burnout are contributing factors for such a belief. Appropriate education and training caregivers can improve care of stroke patients. Understanding the reality of activities a stroke patient can perform will undoubtedly enhance stroke care.

Urinary incontinence in stroke can lead to severe distress to stroke survivors and caregivers. ${ }^{6}$ Approximately 32-79\% of stroke patients at admission, $25-28 \%$ at discharge and $12-19 \%$ till few months after stroke suffer from urinary incontinence. ${ }^{7-13}$ In a study from Taiwan, Wu observed only $11 \%$ respondent to be aware of daily catheter care. ${ }^{14}$ Intriguingly majority $(62 \%)$ of caregivers in our study were aware regarding daily catheter care. This observation is interesting. Catheterization is a common basic procedure done in all wards and we have nursing students and interns rotating in our unit who usually perform this procedure in every ward of the hospital. They may hence be discussing about catheter care more than other elements of stroke care.

Swallowing difficulty, a common problem in stroke, results from stroke affecting the hemisphere with the dominant swallowing projection. ${ }^{15}$ It affects about

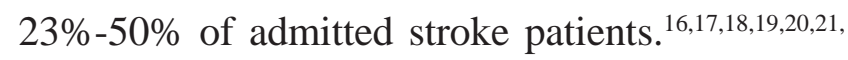
22,23,24,25,26 It can affect the patients' quality of life and may lead to death. In our study, finding 56\% respondents to be aware of nasogastric feeding as a preferable route when swallowing difficulties exist is interesting as the study by $\mathrm{Wu}$ found only $25 \%$ respondents to have the knowledge. ${ }^{14}$ Small number of respondents $(n=17)$ in the study by Wu may have been the reason for such a difference. Nevertheless, as stated above nasogastric feeding is also a common procedure done in all wards and the same reasoning can be applicable here. 
Journal of College of Medical Sciences-Nepal, 2013, Vol-9, No-3,

An optimal diet for stroke patients is low in salt, saturated fat and trans fat, and includes plenty of vegetables, fruit, whole grains and lean protein choices (like fish). ${ }^{27}$ In our study $90 \%$ of respondents were aware of need of highly nutritious diet. However, we did not inquire in detail about the type of diet needed.

Different aspects of communication (language) is affected in approximately $38 \%$ of stroke patients. ${ }^{28}$ Early spontaneous improvement commonly occurs, but early identification of communication problems can assist to monitor improvement. ${ }^{29}$ In our study, 41 (82\%) respondents knew existence of communication impairment in stroke patients but only $38 \%$ were aware to use gestures pictures and objects to encourage communication. Understanding the communication impairment will encourage caregivers institute early treatment and monitor change in communication abilities. Also, recovery of treated individuals has been demonstrated to be couple of times better than untreated patients. ${ }^{29}$

In our study, majority (76\%) knew the occurrence of depression in stroke patients but only 29 (58\%) respondents were aware to provide counseling from health personnel when depression exists. In a review by Robinson and colleague, the prevalence of major depression was $21.7 \%$ and minor depression was $19.5 \%$. Furthermore, depression associated with stroke had greater cognitive impairment and increased mortality. Interestingly, antidepressants proved to improve physical and cognitive recovery and decrease mortality. ${ }^{30}$ Although we observed positive response only in half of respondents, it is definitely encouraging as we did not expect this result in our set up.

Aspiration pneumonia is an important complication of dysphagia, affecting up to $40 \%$ of dysphagic stroke patients during initial 6 months period. ${ }^{31}$ In a study by Dzeiwas et al, acute stroke patients needing tube feeding because of dysphagia, the incidence of pneumonia was $44 \% .{ }^{32}$ In our study 31 (62\%) respondents were aware of pneumonia in stroke patients and 50\% knew deep breathing and coughing exercises prevents infection. In a study by Wu et al, $10 \%$ were concerned about chest care. ${ }^{14}$ Pneumonia is a common concern to public and hence this finding of ours is not surprising. However, we did not inquire specifically about chances of having pneumonia because of dysphagia.

Studies have shown the frequency of pressure sores after stroke to range from $0.7 \%$ in a rehabilitation setting in Singapore ${ }^{33}$ to $18 \%$ in an acute hospital setting in Scotland. ${ }^{34}$ In a study by Kwiczala-Szydowska et al, which evaluated the knowledge of pressure ulcers prevention in 62 caregivers of patient at risk found that only $11 \%$ knew about pressure ulcer, $42 \%$ were not aware of possible pressure ulcer causes, and $54.8 \%$ were not able to mention any pressure ulcer risk factors. ${ }^{35}$ Interestingly, $94 \%$ of respondents in our study were aware about frequent position changing as a basic methods to prevent pressure sore. However, it is said that Petronilho et al in a study from Portugal demonstrated marked lack of knowledge in the areas of prevention of pressure sore amongst caregivers. ${ }^{36}$ Although majority of caregivers in our study had knowledge about pressure ulcer prevention, it may not be reflected in real practice as we come across pressure ulcer in stroke patients in hospital and on follow up. A single factor is very difficult to be blamed for this at present.

Nevertheless, in a country like Nepal where we do not have enough neurologists ${ }^{37}$ and experts to provide proper stroke care, targeting caregivers' training based 
N. Sharma et al. low level of stroke care...

on information provided by this study would be a way to combat stroke related avoidable morbidities and mortalities.

\section{CONCLUSION}

Our study has demonstrated a low level of awareness amongst majority of caregivers interviewed after seven days of hospital stay in different areas of basic care of stroke patients. Further large scale study with in-depth analysis of individual care-item may reveal better understanding of caregivers' knowledge and help institute appropriately targeted intervention for better stroke patients' care and outcome.

\section{LIMITATIONS}

Our study is a cross sectional study where we had only 50 respondents. They were interviewed with selfprepared questions thought to influence stroke care in our setting. It obviously could not incorporate many other important elements of basic stroke care. Also the respondents were interviewed in hospital set-up after 7 days. Stroke patients require continuous care and hence caregivers if interviewed after discharge at home may have different responses. Despite of limitations of our study, it has helped us to understand many important aspects of stroke care. A large scale study with intervention program and assessment is suggested.

\section{REFERENCES}

1. Donnan GA, Fisher M, Macleod M. et al. Stroke. Lancet 2008;371:1612-23.
2. Brereton L. Preparation for family care-giving: stroke as a paradigm case. Journal of Clinical Nursing 1997;6:425-34.

3. Koeing KL, Whyte EM, Munin MC. et al. Stroke-related knowledge and health behaviors among poststroke patients in inpatient rehabilitation. Archives of Physical Medicine and Rehabilitation 2007;88:1214-6.

4. Nayeri ND, Mohammadi S, Arazi T. Examining the level of adherence of therapeutic regime by the family caregivers of stroke patients. Canadian Journal on Medicine 2011;2:87-98.

5. Driscoll A. Managing post-discharge care at home: an analysis of patients' and their carers' perceptions of information received during their stay in hospital. Journal of Advanced Nursing 2000;31:1165-73.

6. Brittain KR, Peet SM, Castleden CM. Stroke and Incontinence. Stroke 1998;29:524-28.

7. Brocklehurst JC, Andrews K, Richards B. et al. Incidence and correlates of incontinence in stroke patients. J Am Geriatr Soc. 1985;33:540-2.

8. Kamouchi M, Ibayashi S, Takaba H. et al. Urinary incontinence in elderly patients in the chronic stage of stroke. Jpn J Geriatr. 1995;32:741-6.

9. Benbow S, Sangster G, Barer D. Incontinence after stroke. Lancet 1991;338:1602-03.

10. Kalra L, Smith DH, Crome P. Stroke in patients aged over 75 years: outcome and predictors. Postgrad Med. 1993;69:33-36. 
Journal of College of Medical Sciences-Nepal, 2013, Vol-9, No-3,

11. Nakayama H, Jørgensen HS, Pedersen PM. et al. Prevalence and risk factors of incontinence after stroke: the Copenhagen stroke study. Stroke 1997;28:58-62.

12. Wade DT, Hewer RL. Outlook after an acute stroke: urinary incontinence and loss of consciousness compared in 532 patients. Q J Med. 1985;56:601-08.

13. Ween JE, Alexander MP, D’Esposito M. et al. Incontinence after stroke in a rehabilitation setting: outcome associations and predictive factors. Neurology 1996;47:659-63.

14. Wu CM. Learning to be a family caregiver for severely debilitated stroke survivors during the first year in Taiwan [dissertation]. University of Iowa; 2009. Available from : http://ir.uiowa.edu/ etd $/ 451$

15. Singh S, Hamdy S. Dysphagia in stroke patients. Postgrad Med J. 2006;82:383-91.

16. Daniels SK, Ballo LA, Mahoney MC. et al. Clinical predictors of dysphagia and aspiration risk: outcome measures in acute stroke patients. Arch Phys Med Rehabil. 2000;81:1030-3.

17. Daniels SK, Brailey K, Priestly DH. et al. Aspiration in patients with acute stroke. Arch Phys Med Rehabil 1998;79:14-9.

18. Johnson E R, McKenzie S W, Sievers A. Aspiration pneumonia in stroke. Arch Phys Med Rehabil1993;74:973-6.

19. Kidd D, Lawson J, Nesbitt R. et al. Aspiration in acute stroke: a clinical study with videofluoroscopy. Q J Med 1993;86:825-9.
20. Gordon C, Hewer RL, Wade DT. Dysphagia in acute stroke. BMJ (Clin Res Ed) 1987;29:5411-4.

21. Mann G, Hankey G J, Cameron D. Swallowing disorders following acute stroke: prevalence and diagnostic accuracy. Cerebrovasc Dis 2000; 10:380-6.

22. Mann G, Hankey GJ, Cameron D. Swallowing function after stroke: prognosis and prognostic factors at 6 months. Stroke 1999;30:744-8.

23. Robbins J, Levin RL. Swallowing after unilateral stroke of the cerebral cortex: preliminary experience. Dysphagia 1988;311-17.

24. Sellars C, Campbell AM, Stott DJ. et al. Swallowing abnormalities after acute stroke: a case control study. Dysphagia 1999;14:2128.

25. Odderson IR, Keaton JC, McKenna BS. Swallow management in patients on an acute stroke pathway: quality is cost effective. Arch Phys Med Rehabil 1995;76:1130-33.

26. Wolfe CD, Taub NA, Woodrow J. et al. Does the incidence, severity, or case fatality of stroke vary in southern England? J Epidemiol Community Health 1993;47:139-43.

27. A caregiver's guide to stroke recovery. March of Dimes Canada. [Internet; cited 2013 Sept 4] Available from: http://www.marchofdimes.ca/ $\mathrm{EN} / \mathrm{p}$ rog r a m s / s r c / D o c u ment s / caregivers_guide_stroke.pdf

28. Pulvermüller F, Neininger B, Elbert T. Constraint-induced therapy of chronic aphasia after stroke. Stroke 2001;32:1621-6. 
N. Sharma et al. low level of stroke care.

29. Robey RR. The efficacy of treatment for aphasic persons: a meta-analysis. Brain Lang. 1994;47:582- 608 .

30. Robinson RG, Spalletta G. Poststroke Depression: A Review. Can J Psychiatry 2010;55:341-9.

31. Mann G, Hankey GJ, Cameron D. Swallowing Function After Stroke: Prognosis and Prognostic Factors at 6 Months. Stroke;1999;30:744-8.

32. Dzeiwas R, Ritter M, Schilling M. et al. Pneumonia in acute stroke patients fed by nasogastric tube. J Neurol Neurosurg Psychiatry 2004;75:852-6.

33. Doshi VS, Say JH, Young SH. et al. Complications in stroke patients: a study carried out at the Rehabilitation Medicine Service, Changi General Hospital. Singapore Med J. 2003;44:643-52.
34. Davenport RJ, Dennis MS, Wellwood I. et al. Complications after acute stroke. Stroke 1996;27:415-20.

35. Kwiczala-Szydowska S, Skalska A, Grodzicki T. Pressure ulcer prevention-evaluation of awarness in families of patients at risk. Przegl Lek. 2005;62:1393-7.

36. Oliveira MF, Campos MJ, Padilha JM. Et al. Exploring the family caregiving phenomenon in nursing documentation. Online J Nursing Informatics 2011;15(1) [Cross-Reference]

37. Thapa L. A plea from Nepal. Int J Stroke. 2011;6:2:98. (Editorial).

\section{ACKNOWLEDGEMENT}

I would like to thank CMS-TH, Neurology staffs, Emma Sharma and friends for helping me in conducting this study. 